\title{
Search for Electrospun Nanofiber Materials Matching The Mechanical Properties of Native Aortic Valve
}

\author{
Martins Kalejs, Peteris Stradins, Romans Lacis, Iveta Ozolanta, Modra Murovska, and Vladimir \\ Kasyanov
}

\begin{abstract}
Porous electrospun nanofiber materials are very promising as matrixes for heart valve tissue engineering. The perfect material for this purpose has to be both mechanically strong and deformable at the same time.

Materials from gelatin, polyurethane (PUR), polylactic acid (PLA) and polycaprolactone (PCL) made in several density variants were analyzed using uniaxial tensile tests and compared to mechanical properties of porcine aortic valve (AV) leaflets in radial and circumferential directions.

In circumferential direction modulus of elasticity $(\mathrm{E})$ of $\mathrm{AV}$ is 9.7 $\pm 1.3 \mathrm{MPa}$ and $-1.0 \pm 0.2 \mathrm{MPa}$ in radial. Ultimate strain and stress is $44.8 \pm 5.9 \%$ and $2.3 \pm 0.6 \mathrm{MPa}$ in circumferential and $95.6 \pm 31.4 \%$ and $0.5 \pm 0.2 \mathrm{MPa}$ in radial direction for $\mathrm{AV}$. Closest of the materials to native $\mathrm{AV}$ in circumferential direction was PUR with area density $6.2 \mathrm{~g} / \mathrm{m}^{2}$ showing $E$ of $3.9 \pm 0.5 \mathrm{MPa}$, ultimate stress and strain - $5.3 \pm 1.68 \mathrm{MPa}$ and $141.8 \pm 43.9 \%$ respectively. Closest to radial direction was gelatin with area density $5.7 \mathrm{~g} / \mathrm{m}^{2}$ showing $E$ of $0.64 \pm 0.14 \mathrm{MPa}$, ultimate stress and strain $-0.38 \pm 0.05 \mathrm{MPa}$ and $82.53 \pm 10.20 \%$ respectively.

Native AV leaflets have a non-linear and anisotropic response to stress in uniaxial tensile tests. To model their mechanical properties we suggest using a combined material made of gelatin and PUR with their fibbers predominantly orientated in perpendicular directions.
\end{abstract}

Index Terms - Heart valve, mechanical properties, nanofiber materials, tissue engineering.

\section{INTRODUCTION}

Heart valve prostheses, both mechanical and biological, have saved lives and increased quality of life to millions of patients all over the world since their introduction in 1960's. However, despite all the benefits offered by prosthetic heart valves, there are serious drawbacks for both types of prostheses in the long run, namely the often very serious and even fatal side-effects of prolonged anticoagulation required for mechanical prostheses and structural degeneration of

Manuscript received January 30, 2013; revised March 5, 2013. This work was in part supported by Latvian National Research Program in Medicine 2010.-2013., project "Research of Biomaterials for Treatment of Cardiovascular diseases" and European Social Found [Agreement Nr. 2009/0221/1DP/1.1.1.2.0/09/APIA/VIAA/074].

M. K. and P. S. were with Augusts Kirhensteins Institute of Microbiology and Virology, Ratsupites str. 5, Riga, Latvia and still are with Department of Cardiac Surgery, Pauls Stradins Clinical University Hospital, Pilsonu str. 13, Riga, Latvia (e-mail: martins.kalejs@stradini.lv, peteris.stradins@stradini.lv).

R. L. is with Department of Cardiac Surgery, Pauls Stradins Clinical University Hospital, Pilsonu str. 13, Riga, Latvia (e-mail: valentina@stradini.lv).

I. O. and V. K. are with Laboratory of biomechanics, Riga Stradins university, Dzirciema str. 16, Riga, Latvia (e-mail: iveta.ozolanta@RSU.1v, V. K. e-mail: Kasyanov@latnet.lv).

M. M. is with Augusts Kirhensteins Institute of Microbiology and Virology, Ratsupites str. 5, Riga, Latvia (e-mail: modra.murovska@rsu.lv). bioprosthetic valves [1]. Tissue engineered heart valves made using autologous stem cells could provide an answer to these problems offering a viable substitute for an individual's diseased heart valve which would require no anticoagulation and, being living tissue, would be resistant to structural degeneration. Even further, tissue engineered heart valves raise new hopes for valve replacement in children and adolescents as potentially having the capability to grow together with the patient to adapt to its hemodynamic needs.

There are several options for tissue engineering of complex biological structures like a heart valve but all of them involve a sort of "pre-made" scaffold - working as a matrix for autologous stem cells to be seeded on, which allows the formation of the complex three dimensional structure specific for heart valve leaflets. Two types of scaffolds are used most often - decellularized heart valve leaflets of human or animal origin and synthetic polymer material scaffolds [2]. Decellularized material comes with all the difficulties of a foreign biological material, namely immunogenicity requiring chemical treatment of the tissue which again negatively influences repopulation of this material with cells as well as impedes further biodegradation of the scaffold. Polymeric scaffolds hence hold a great promise as matrices for tissue engineering. Electrospun nanofiber materials are especially promising as matrixes, because their fiber diameter, material thickness, porosity and even fiber orientation can be easily controlled. There are many biocompatible polymeric materials which can be used for creating a scaffold with well-known properties and well known degradation times in vivo which have been used for surgical implant production for many years. Albeit not only biocompatibility is important for this material but also the mechanical features:

It has to be strong enough to withhold the pressure after implantation; deformable enough for better distribution of shear stress along its surface and for stimulation of fiber production by connective tissue cells on these matrices.

As it is well known and has been demonstrated experimentally heart valve interstitial cells produce extracellular matrix (ECM) components including fibers much more effectively when receiving an appropriate mechanical stimulus [3]. This is one of the reasons why heart valve tissue engineering is moving more towards cellularization of scaffolds in vivo, after implantation, not in specially constructed bioreactors for weeks before actual implantation. Such strategy not only guarantees perfect conditions for cell growth and ECM production on the valve leaflet scaffolds, but also dramatically reduces the time required for preparing a heart valve substitute, as well as reduces costs of such a valve. On the other hand, if the 
material is implanted in the patient immediately or just a few hours after initial seeding with autologous stem cells, it is clear that the scaffold used has to be mechanically strong enough to withstand the blood pressure in the aortic root and it has to degrade slower than the newly recruited interstitial cells manage to produce a new ECM fibrous structure. In principle the mechanical properties of the polymer material scaffold have to confirm to those of the native aortic valve. It can be mechanically stronger, but not for the price of deformability, because it is crucial for ECM production by valve interstitial cells.

Native aortic valve cusps are an anisotropic material with differing mechanical properties in the radial and circumferential directions. Which are determined by collagen fibers predominantly aligned and forming bundles in circumferential direction, whereas elastin fibers are orientated mainly in a perpendicular - radial direction [4].

\section{THE AIM}

Objective of our study was to find an ideal polymer nanofiber material for use as a matrix for heart valve tissue engineering purposes with mechanical properties matching those of the native aortic valve leaflets as close as possible.

\section{MAterials AND Methods}

Electrospun nanofiber materials produced as nanofiber material sheets (custom-made by Elmarco s.r.o., Liberec, Czech Republic) from gelatin, polyurethane (PUR), polylactic acid (PLA) and polycaprolactone (PCL) in several density variants were analyzed using uniaxial tensile tests. Data were compared to mechanical properties of native porcine aortic valve (AV) leaflets in radial and circumferential directions. Native porcine AV has been shown to differ from human $\mathrm{AV}$, but its mechanical properties are still comparable with those of the human AV [5]. We determined their mechanical properties using uni-axial tensile tests with a universal testing machine Zwick/Roell BDO-FB0.5TS (Zwick GmbH \& Co, Ulm, Germany) equipped with test Xpert software (see Fig.1). The tested nanofiber scaffold and valve leaflet material was cut into $3.5 \mathrm{~mm}$ wide and 15 - $20 \mathrm{~mm}$ long specimens. Leaflets were cut in circumferential and radial directions (Fig. 2). The thickness of all specimens was measured using a cathetometer MK-6 (LOMO, Saint Petersburg, Russia) with a precision of $\pm 0.01 \mathrm{~mm}$. Data are presented as means \pm standard deviation.

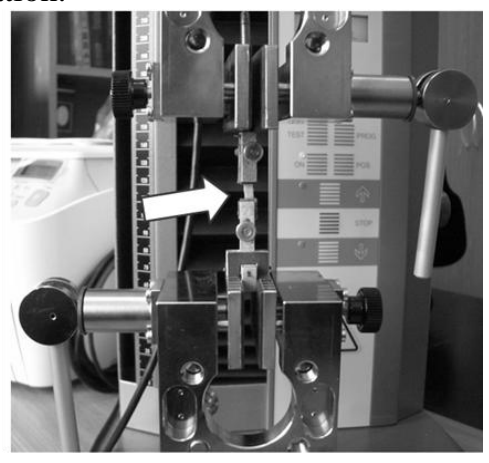

Fig. 1. The setup for uni-axial tensile tests with a universal testing machine Zwick/Roell BDO-FB0.5TS (Zwick GmbH \& Co, Ulm, Germany) equipped with test Xpert software. Analyzed material sample marked with an arrow.
Materials tested are as follows:

- PUR - poliurethane $-6.2 \mathrm{~g} / \mathrm{m}^{2}$ and $10.4 \mathrm{~g} / \mathrm{m}^{2}$

- PCL - polycaprolactone $-3.86 \mathrm{~g} / \mathrm{m}^{2}$ and $12 \mathrm{~g} / \mathrm{m}^{2}$ and $15.7 \mathrm{~g} / \mathrm{m}^{2}$

- PLA - polylactic acid $-5.2 \mathrm{~g} / \mathrm{m}^{2}$ and $11 \mathrm{~g} / \mathrm{m}^{2}$

- Gelatin - $5.7 \mathrm{~g} / \mathrm{m}^{2}$

- Samples from 5 porcine aortic valves, obtained from a slaughterhouse within $24 \mathrm{~h}$ after animals death.

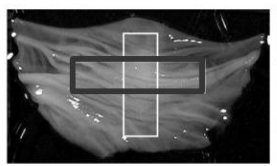

circumferential

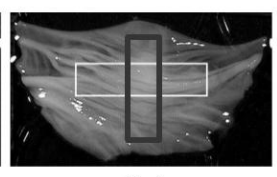

radial
Fig. 2. Definition of the testing directions of aortic valve leaflets.

\section{RESULTS}

Results of the mechanical properties testing of different nanofiber materials are summarized in Table I which also includes corresponding data on porcine aortic valve leaflets. In circumferential direction modulus of elasticity $(\mathrm{E})$ of native porcine aortic valve is $9.7 \pm 1.3 \mathrm{MPa}$ and $-1.0 \pm 0.2 \mathrm{MPa}$ in radial. Ultimate strain and stress is $44.8 \pm 5.9 \%$ and $2.3 \pm 0.6$ $\mathrm{MPa}$ in circumferential and $95.6 \pm 31.4 \%$ and $0.5 \pm 0.2 \mathrm{MPa}$ in radial direction for native leaflets. Closest of the materials to match the mechanical properties of porcine aortic valve in circumferential direction was PUR with area density $6.2 \mathrm{~g} / \mathrm{m}^{2}$ showing $\mathrm{E}$ of $3.9 \pm 0.5 \mathrm{MPa}$ with ultimate stress and strain $5.3 \pm 1.68 \mathrm{MPa}$ and $141.8 \pm 43.9 \%$ respectively (shaded in Table I). The stress-strain curves of PUR $6.2 \mathrm{~g} / \mathrm{m} 2$ samples in comparison with native porcine aortic valve in circumferential direction can be seen in Fig. 3, from which we can appreciate that PUR as a synthetic material has nearly linear stress-strain response, but nevertheless its slope and numerical values are comparable with those of native porcine valve. Closest to match radial direction was gelatin with area density $5.7 \mathrm{~g} / \mathrm{m}^{2}$ showing $\mathrm{E}$ of $0.64 \pm 0.14 \mathrm{MPa}$, ultimate stress and strain - $0.38 \pm 0.05 \mathrm{MPa}$ and $82.53 \pm 10.20 \%$ respectively (shaded in Table I). The stress-strain curves of gelatin with area density $5.7 \mathrm{~g} / \mathrm{m}^{2}$ samples in comparison with native porcine aortic valve in radial direction can be seen in Fig. 4, where we can observe nearly exact match of the material properties. Although, as mentioned before, elastin fibres are predominantly oriented in the radia direction, not collagen from which gelatin is manufactured.

TABLE I: SUMMARY OF MECHANICAL PROPERTIES TESTING OF VARIOUS POLYMER NANOFIBER MATERIALS, SHOWING THEIR RESPECTIVE MODULUS OF Elasticity (E), Ultimate Stress $(\Sigma \mathrm{M})$ AND Ultimate Strain $(\Sigma \mathrm{X})$

\begin{tabular}{lccc} 
& E $(\mathbf{M P a})$ & $\boldsymbol{\sigma}$ M (Mpa) & $\boldsymbol{\sigma} \mathbf{X}(\mathbf{\%})$ \\
\hline $\begin{array}{l}\text { Porcine aortic valve, } \\
\text { circumferential }\end{array}$ & $9.7 \pm 1.3$ & $2.3 \pm 0.6$ & $44.8 \pm 5.9$ \\
\hline $\begin{array}{l}\text { Porcine aortic valve, } \\
\text { radial }\end{array}$ & $1.0 \pm 0.2$ & $0.5 \pm 0.2$ & $95.6 \pm 31.4$ \\
\hline PCL $3.86 \mathrm{~g} / \mathrm{m}^{2}$ & $0.88 \pm 0.25$ & $0.2 \pm 0.03$ & $42.8 \pm 5.08$ \\
\hline PCL $12 \mathrm{~g} / \mathrm{m}^{2}$ & $0.48 \pm 0.12$ & $0.09 \pm 0.02$ & $20.79 \pm 3.31$ \\
\hline PCL $15.7 \mathrm{~g} / \mathrm{m}^{2}$ & $1.3 \pm 0.2$ & $0.3 \pm 0.05$ & $37.9 \pm 2.46$ \\
\hline PLA $5.2 \mathrm{~g} / \mathrm{m}^{2}$ & $3.35 \pm 0.48$ & $0.55 \pm 0.03$ & $41.94 \pm 3.67$ \\
\hline PLA $11 \mathrm{~g} / \mathrm{m}^{2}$ & $0.23 \pm 0.03$ & $0.14 \pm 0.01$ & $54.94 \pm 8.15$ \\
\hline Gelatin $5.7 \mathrm{~g} / \mathrm{m}^{2}$ & $0.64 \pm 0.14$ & $0.38 \pm 0.05$ & $82.53 \pm 10.20$ \\
\hline PUR $6.2 \mathrm{~g} / \mathrm{m}^{2}$ & $3.9 \pm 0.5$ & $5.3 \pm 1.68$ & $141.8 \pm 43.9$ \\
\hline PUR $10.4 \mathrm{~g} / \mathrm{m}^{2}$ & $4.55 \pm 0.78$ & $7.65 \pm 1.65$ & $181.06 \pm 39.83$ \\
\hline
\end{tabular}




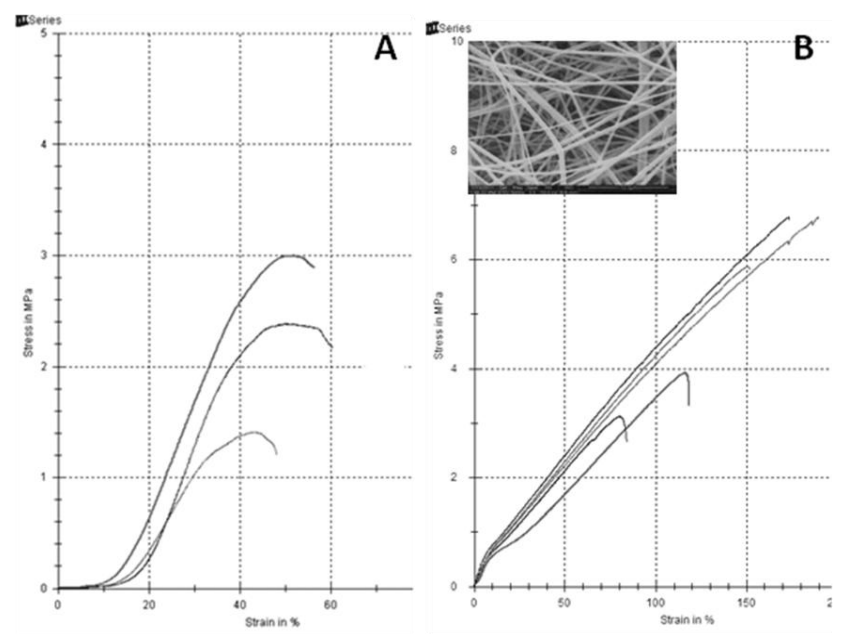

Fig. 3. Stress - strain curves of porcine aortic valve in circumferential direction (A) and PUR $6.2 \mathrm{~g} / \mathrm{m}^{2}(\mathrm{~B})$. Inset - scanning electron microscopy image of PUR nanofibers.
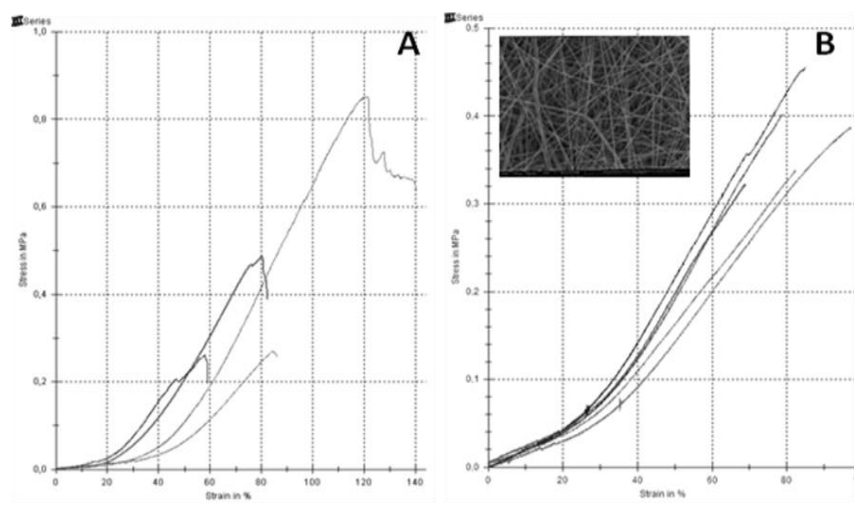

Fig. 4. Stress - strain curves of porcine aortic valve in radial direction (A) and gelatine $5.7 \mathrm{~g} / \mathrm{m}^{2}(\mathrm{~B})$. Inset - scanning electron microscopy image of gelatine nanofibers.

\section{DISCUSSION}

To our best knowledge there are no published reports on mechanical properties of nanofiber materials directly comparing them to native aortic valve leaflets. Several polymer materials are tested for tissue engineering purposes for more than a decade now, such as polyglactin [6], polyglycolic acid (PGA) [7], polylactic acid (PLA) [8], polycaprolactone (PCL) [9], etc [2]. There is a notion that the mechanical properties of scaffolds used in heart valve tissue engineering should mimic the native valve tissue and there have been attempts to reproduce that [10], comparing their results to the native pulmonary valve leaflets.

In our study we have found that two polymers very commonly used in tissue engineering and for surgical implants, namely PCL and PLA both lack mechanical strength as well as deformability required for valve leaflet scaffolds. Both PCL and PLA ultimate stress values were more than 4-fold smaller than that of the native porcine aortic valve in circumferential direction and maximum strain near 2 -fold smaller than that of the native valve in radial direction which renders these two materials not perfectly suitable as a matrix for heart valve leaflets. In contrast PUR has the mechanical strength required for circumferential direction to withhold the pressure loading during diastole of the heart cycle, but it is rather too stiff when compared to native valve tissue in radial direction. Gelatin is deformable enough and not too stiff as judged by modulus of elasticity and maximum strain (see Table I), but lacks the mechanical strength with a maximum stress of only $0.38 \mathrm{MPa}$. For this reason we have developed an idea of using a composite nanofiber scaffold combining both PUR and gelatin fibers in a single material mainly orientated in perpendicular fashion, like depicted in Fig. 5, with two gelatin layers on the outside because of superior biocompatibility and a PUR layer in the middle.

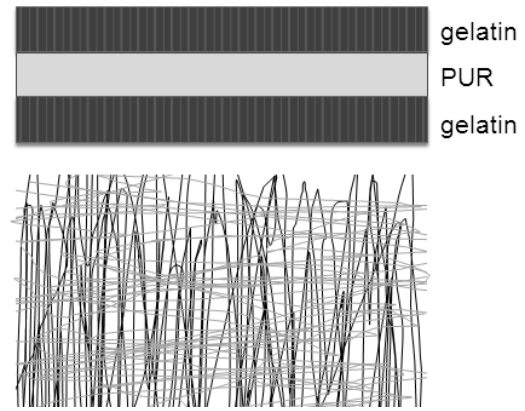

Fig. 5. A schematic view of a proposed combined nanofiber matrix, showing a transsectional view (top) and a view from above (bottom).

\section{CONCLUSION}

Native AV leaflets have a non-linear and anisotropic response to stress in uniaxial tensile tests. Hence to model as precisely as possible their mechanical properties we suggest to use a combined material made in a sandwich fashion with layers of gelatin on the outside and PUR in the middle with their fibers predominantly orientated in perpendicular directions (Fig. 5).

The other tested materials PLA and PCL either lacked strength to mimic leaflets in circumferential direction or deformability required for the radial direction.

\section{REFERENCES}

[1] I. Vesely, "The evolution of bioprosthetic heart valve design and its impact on durability," Cardiovascular Pathology, vol. 12, pp. 277-286, Sep.- Oct. 2003.

[2] A. Mol, A. I. Smits, C. V. Bouten, and F. P. Baaijens, "Tissue engineering of heart valves: advances and current challenges," Expert Rev Med Devices, vol. 6, no. 3, pp. 259-275, May 2009.

[3] A. M. Quinlan and K. L. Billiar, "Investigating the role of substrate stiffness in the persistence of valvular interstitial cell activation," $J$. Biomed Mater Res A, vol. 100, no. 9, pp. 2474-2482, Sep. 2012.

[4] P. Stradins, R. Lacis, I. Ozolanta, B. Purina, V. Ose, L. Feldmane, and V. Kasyanov, "Comparison of biomechanical and structural properties between human aortic and pulmonary valve," Eur J. Cardiothorac Surg, vol. 26, no. 3, pp. 634-639, Sep. 2004.

[5] M. Kalejs, P. Stradins, R. Lacis, I. Ozolanta, J. Pavars, and V. Kasyanov, "St Jude Epic heart valve bioprostheses versus native human and porcine aortic valves - comparison of mechanical properties," Interact Cardiovasc Thorac Surg, vol. 8, no. 5, pp. 553-556, May 2009.

[6] T. Shinoka, C. K. Breuer, R. E. Tanel, G. Zund, T. Miura, and P. X. Ma et al., "Tissue engineering heart valves: valve leaflet replacement study in a lamb model," Ann. Thorac. Surg, vol. 60, no. Suppl. 3, pp. S513-S516, Dec. 1995.

[7] T. Shinoka, P. X. Ma, D. Shum-Tim, C. K. Breuer, R. A. Cusick, and G Zund et al., "Tissue engineered heart valves. Autologous valve leaflet replacement study in a lamb model," Circulation, vol. 94, pp. II164-II168, Nov. 1996.

[8] T. Shinoka, D. Shum-Tim, P. X. Ma, R. E. Tanel, N. Isogai, and R Langer et al., "Creation of viable pulmonary artery autografts through tissue engineering," J. Thorac. Cardiovasc. Surg, vol. 115, pp. 536-546, Mar. 1998 
[9] C. Del Gaudio, M. Grigioni, A. Bianco, and G. De Angelis, "Electrospun bioresorbable heart valve scaffold for tissue engineering," Int J Artif Organs, vol. 31, no. 1, pp. 68-75, Jan. 2008.

[10] T. Courtney, M. S. Sacks, J. Stankus, J. Guan, and W. R. Wagner, "Design and analysis of tissue engineering scaffolds that mimic soft tissue mechanical anisotropy," Biomaterials, vol. 27, no. 19, pp. 3631-3638, July 2006.

Martins Kalejs was born in Talsi, Latvia, 1981. Received MD at Riga Stradins University, RigaLatvia in 2006. Currently has finished his formal $\mathrm{PhD}$ studies and is a PhD candidate at Riga Stradins University. His main research interests are biomechanics of the cardiovascular system, mainly heart valves as well as modeling of the cardiovascular system.

He currently is a staff surgeon at the Department of Cardiac Surgery at Pauls Stradins Clinical University Hospital,Riga, Latvia and a researcher at Riga Stradins University, Riga, Latvia.

Dr. Kalejs is a member of several local and international professional societies including but not limited to: European Society of Cardiology, European Association for Cardio-Thoracic Surgery, Scandinavian Association for Thoracic Surgery and others.

Peteris Stradins was born in Riga, Latvia, 1971. Received MD at Medical Academy Of Latvia, Riga, Latvia in 1995. PhD in Medicine in the field of biomechanics of the human cardiovascular system from Riga Stradins University, Riga, Latvia in 2004. Authors main research interests are biomechanics of the cardiovascular system, mainly heart valves and their components as well as clinical investigation.

He currently holds a position of an associate professor of Cardiac Surgery at Riga Stradins University, Riga, Latvia as well as he is Chief of the Department of Cardiac Surgery at Pauls Stradins Clinical University Jospital, Riga, Latvia.

Prof. Stradins is a member of many local and international professional societies including but not limited to: European Society of Cardiology, European Association for Cardio-Thoracic Surgery, Society of Thoracic Surgeons, European Society For Clinical Investigation and many others.

Romans Lacis was born in Kuldiga, Latvia, 1946. Received MD at Riga Medical Institute in 1970. Dr.med. (Candidate of Science in former USSR) at Riga Medical Institute in 1974 and Dr.habil.med (Doctor of Science in former USSR) at Riga Medical Institute in 1987. His main research interests are related to mechanics and ultrastructure of prosthetic heart valves.

He currently is a professor of Cardiac Surgery at Riga Stradins University, Riga, Latvia as well as head of the Centre of Cardiac Surgery at Pauls Stradins Clinical University Hospital in Riga, Latvia.

Prof. Lacis is a member of many local and international professional societies: European Society of Cardiology, European Association for
Cardio-Thoracic Surgery, Society of Thoracic Surgeons, European Society for Cardiovascular Surgery and many others. He is the author of 200+ publications and has received many awards.

Iveta Ozolanta was born in Riga, Latvia, 1948. Received MD at Riga Medical Institute in 1973. Dr.med. (Candidate of Science in former USSR) at Kaunas Medical Academy, Lithuania in 1983 and Dr.habil.med (Doctor of Science in former USSR) at Medical Academy Of Latvia, Riga in 1998. Her research interests are centered on mechanical properties of various biological materials, those of the cardiovascular system being of special interest.

She currently is a professor and Vice-rector for Science at Riga Stradins University, Riga, Latvia. She is a Member of the Board in Latvian Association of Professors. She has served as a Coordinator of EU 5th and 6th Framework ERA-NET-AGE programs.

Prof. Ozolanta is a member of many local and international professional societies: European Society of Biomechanics, European Society of Tissue Engineering among many others.

Modra Murovska was born in Saldus, Latvia, 1949. Received MD at Riga Medical Institute in 1972. Dr.med. (Candidate of Science in former USSR) at Cancer Research Centre, USSR Academy of Medical Sciences, Moscow, Russia,1978. Her main research interests are centered around various onco-viruses.

She currently holds a position of an associate professor at Riga Stradins University, Riga, Latvia and is the Acting Director and Senior Researcher of August Kirchenstein Institute of Microbiology and Virology of Riga Stradins University, Riga, Latvia.

Prof. Murovska is a member of many local and international professional societies: American Society for Microbiology, European Society for Virology, European Association for Cancer Research among many others.

Vladimir Kasyanov was born in Peremyshlyany, Ukraine, 1946. Reeived MSc in Civil Engineering at Riga Polytechnic Institute, Riga, Latvia, 1969, and Candidate of Engineering Sciences (Ph.D.) at Institute of Polymer Mechanics, Latvian Academy of Science, Riga, 1977 followed by Doctor of Engineering Sciences (Dr. habil.sc.ing.) at Latvian Scientific Research Institute of Traumatology and Orthopedics, Riga, 1989. His main research interests are soft tissue biomechanics and tissue engineering.

He currently is a professor at Riga Stradins University, Riga, Latvia as well as the head of Laboratory of Biomechanics at Institute of Anatomy and Anthropology of Riga Stradins University, Riga, Latvia.

Prof. Kasyanov is a member of many local and international professional societies: European Tissue Engineering Society, European Biomechanics Society, International Community for Composites Engineering among many others. 